ISBN 978-93-86878-07-6

8th International Conference on Agricultural, Environment, Biology and Medical Sciences

(AEBMS-2017)

Dec. 21-22, 2017 Dubai (UAE)

\title{
Apoptotic Bax Gene Expression in Glioblastoma Cells Exposed to Estradiol valerate
}

\author{
Farahmandlou N, Noroozi S* \\ Nooshin Farahmandlou (PhD) is with the Department of Basic Sciences, Faculty of Pharmacy, Pharmaceutical \\ Sciences Branch, Islamic Azad University, Tehran - Iran (IAUPS ) (e-mail: tnaji2002@gmail.com) \\ (e-mail: n.farahmandlou@yahoo.com). \\ Sanaz Noroozi (MSc) (*corresponding author) is with Department of Biology, Faculty of Basic Sciences, \\ GhiamDasht (East Tehran Branch), Islamic Azad University, Tehran-Iran (Sayana.nrzi@ gmail.com)
}

\begin{abstract}
Cancers may be influenced by sex steroids in vivo and in vitro. This research aims to determine the effects of estradiol valerate on Bax gene expression level in glioblastoma (A172) cells in cell culture. A172 cells were exposed to cytotoxic dose $(0.1 \mathrm{mg} / \mathrm{ml})$ of estradiol valerate solution. Real time PCR was used to measure Bax gene expression level. Our results indicated that exposure to $0.1 \mathrm{mg} / \mathrm{ml}$ of estradiol valerate led to significant increase in viability compared to control cells $(P<0.05)$. Our findings indicated that cytotoxic dose of estradiol have apoptotic effects on brain tumor (A172) cells in cell culture.
\end{abstract}

Keywords: Estradiol, A172, Bax.

\section{Introduction}

Glioblastoma is the most common and aggressive primary brain tumor in adults. Defining histopathologic features are necrosis and endothelial proliferation, resulting in the assignment of grade IV, the highest grade in the World Health Organization (WHO) classification of brain tumors. The classic clinical term "secondary glioblastoma" refers to a minority of glioblastomas that evolve from previously diagnosed WHO grade II or grade III gliomas [1].

Glioblastomas have an annual incidence of 5.26 per 100,000 population or 17,000 new diagnoses per year. These tumors are typically associated with a dismal prognosis and poor quality of life. Glioblastoma also remains a difficult cancer to treat, although therapeutic options have been improving. Optimal management requires a multidisciplinary approach and knowledge of potential complications from both the disease and its treatment [2].

Estrogen exhibits a broad spectrum of physiological functions ranging from regulation of the menstrual cycle and reproduction to modulation of bone density, brain function, and cholesterol mobilization. Despite the beneficial actions of endogenous estrogen, sustained exposure to exogenous estrogen is a well-established risk factor for various cancers [3]-[6].

This research was exerted to determine the apoptotic effects of cytotoxic dose of estradiol Bax gene expression level in glioblastoma (A172) cells in cell culture.

\section{Material and methods}

A172 cells (glioblastoma cell line) were purchased from National Cell Bank of Iran (Pasteur Institute, Tehran, Iran). Cells were grown and incubated in standard situation. Then, cells were sub-cultured into $75 \mathrm{~cm} 2$ flasks, $96-$ well plates or 6-well plates. Cytotoxicity of different doses of the estradiol was assayed using MTT method. 
Real time PCR was used to measure Bax gene expression level. Analyses were conducted using the SPSS20 and ANOVA.

\section{Results}

MTT assay showed that $0.1 \mathrm{mg} / \mathrm{ml}$ of estradiol valerate has cytotoxic effects on glioblastoma cells. Exposure to $0.1 \mathrm{mg} / \mathrm{ml}$ of estradiol valerate led to significant increase in bax gene expression level in glioblastoma cells compared to control cells $(\mathrm{P}<0.001)$. (Figure I).

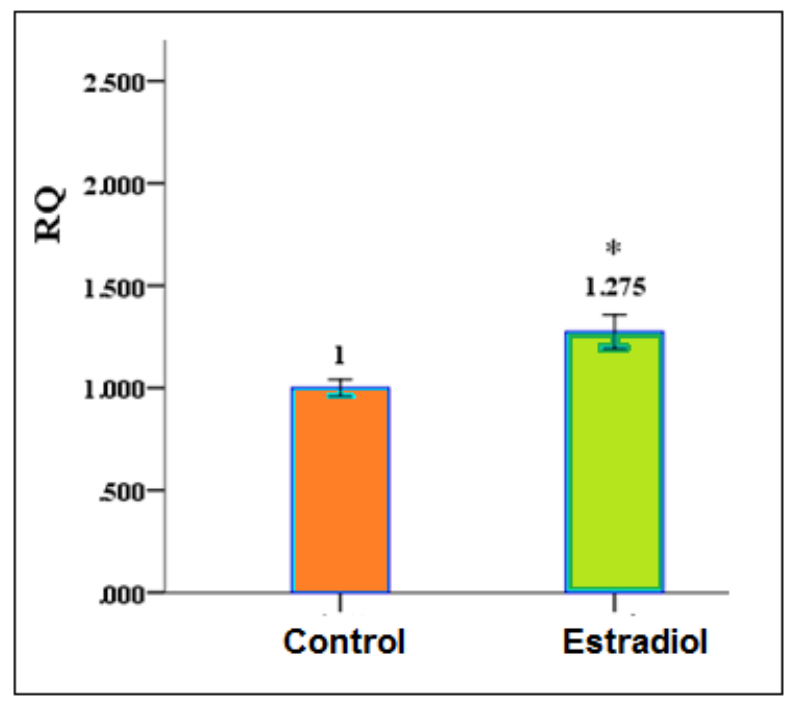

Fig. 1: Bax gene expression level in A172 cells exposed to cytotoxic dose of estradiol compared to control group. * indicates significant difference compared to control group at $\mathrm{P}<0.05$.

\section{Discussion}

In our study we have shown that cytotoxic dose of estradiol have apoptotic effects on brain tumor (A172) cells in cell culture. It has been suggested that female sex hormones influence the development and growth of brain tumors, particularly meningiomas. A higher female:male ratio in some types of nervous system malignancies, especially during the female reproductive years[7].

The investigations on the effects of phyto-oestrogens on various tissues have revealed that these diverse molecules may improve human health, particularly by protecting against certain chronic diseases [8]. It has also been reported that estrogen may have protecting effects against various cancers [9]-[10]. The research revealed that estrogen has improving effects on glioblastoma treatment [11].

In contrast to our findings there are reports indicating that estrogens are involved in cancer development. It has been shown that estrogen has critical role in development of breast cancer [12]. Greater exposure to estrogens may be a risk factor for thyroid cancer [13]. Further research are required to clarify whether estrogens have advantage in treatment of cancers, in particular glioblastoma cancer.

\section{Conclusion}

Our finding indicated that the cytotoxic dose of estradiol valerate has apoptotic effects on glioblastoma cells in cell culture.

\section{Acknowledgment}

We appreciate all who helped us to exert this study.

\section{References}

[1] Wirsching HG, Galanis E, Weller M. Glioblastoma. Handb Clin Neurol. 2016;134:381-97.

[2] Omuro A, DeAngelis LM. Glioblastoma and other malignant gliomas: a clinical review. JAMA. 2013 Nov 6;310(17):1842-50. 
[3] Liang J, Shang Y. Estrogen and cancer. Annu Rev Physiol. 2013;75:225-40.

[4] Barakat R, Oakley O, Kim H, Jin J, Ko CJ. Extra-gonadal sites of estrogen biosynthesis and function. BMB Rep. 2016 Sep;49(9):488-96.

[5] Mauvais-Jarvis F, Clegg DJ, Hevener AL. The role of estrogens in control of energy balance and glucose homeostasis. Endocr Rev. 2013 Jun;34(3):309-38

[6] Zhao Z, Wang H, Jessup JA, Lindsey SH, Chappell MC, Groban L. Role of estrogen in diastolic dysfunction. Am J Physiol Heart Circ Physiol. 2014 Mar 1;306(5):H628-40.

[7] Helseth A. Incidence and survival of intracranial meningioma patients in Norway 1963-1992. Neuroepidemiology 1997;16:53-9.

[8] Anderson JJ, Anthony M, Messina M, Garne SC. Effects of phyto-oestrogens on tissues. Nutr Res Rev. 1999 Jun;12(1):75-116

[9] Suba Z. Circulatory estrogen level protects against breast cancer in obese women. Recent Pat Anticancer Drug Discov. 2013 May;8(2):154-67.

[10] Honma N, Hosoi T, Arai T, Takubo K. Estrogen and cancers of the colorectum, breast, and lung in postmenopausal women. Pathol Int. 2015 Sep;65(9):451-9.

[11] Plunkett RJ, Lis A, Barone TA, Fronckowiak MD, Greenberg SJ. Hormonal effects on glioblastoma multiforme in the nude rat model. J Neurosurg. 1999 Jun;90(6):1072-7.

[12] Samavat H, Kurzer MS. Estrogen metabolism and breast cancer.Cancer Lett. 2015 Jan 28;356(2 Pt A):231-43.

[13] Zahid M, Goldner W, Beseler CL, Rogan EG, Cavalieri EL.Unbalanced estrogen metabolism in thyroid cancer. Int J Cancer. 2013 Dec 1;133(11):2642-9. 